Uniwersytet PrzyrodniczoHumanistyczny w Siedlcach

Siedlce University of Natural Sciences and Humanities

https://bazawiedzy.uph.edu.pl

\begin{tabular}{|l|l|}
\hline Publikacja / Publication & $\begin{array}{l}\text { From exclusion to inclusion of people with disabilities, } \\
\text { Trębicka-Postrzygacz Beata Maria, Roguska Agnieszka, Antas-Jaszczuk Alicja }\end{array}$ \\
\hline $\begin{array}{l}\text { DOI wersji wydawcy / Published } \\
\text { version DOI }\end{array}$ & http://dx.doi.org/10.21125/iceri.2018.0211 \\
\hline $\begin{array}{l}\text { Adres publikacji w Repozytorium } \\
\text { URL / Publication address in } \\
\text { Repository }\end{array}$ & https://bazawiedzy.uph.edu.pl/info/article/UPH5092eb0b7d484d36a5637062d4a234c8/ \\
\hline $\begin{array}{l}\text { Data opublikowania w Repozytorium } \\
\text { / Deposited in Repository on }\end{array}$ & 22 paź 2021 \\
\hline Rodzaj licencji / Type of licence & Attribution-NoDerivs (CC BY-ND 3.0) C \\
\hline & $\begin{array}{l}\text { Trębicka-Postrzygacz Beata Maria, Roguska Agnieszka, Antas-Jaszczuk Alicja: From } \\
\text { exclusion to inclusion of people with disabilities, In: ICERI 2018 Proceedings : 11 th } \\
\text { International Conference of Education, Research and Innovation, 12-14 November } \\
\text { 2018, Seville, Spain / Gómez Chova L., López Martínez A., Candel Torres I. (eds.), } \\
\text { ICERI Proceedings, 2018, IATED Academy, ISBN 9788409059485, pp. 4869-4874, } \\
\text { DOI:10.21125/iceri.2018.0211 }\end{array}$ \\
\hline
\end{tabular}




\title{
FROM EXCLUSION TO INCLUSION OF PEOPLE WITH DISABILITIES
}

\author{
B. Trębicka-Postrzygacz, A. Roguska, A. Antas-Jaszczuk \\ Siedlce University of Natural Sciences and Humanities (POLAND)
}

\begin{abstract}
The following monograph is an attempt towards multi-context deliberations on the issue of exclusion and inclusion of people with disabilities. It draws attention to complexity and significance of the phenomena of contemporary scientific and social discourse. The article includes general guidelines for educational procedures and refers to the tradition of Polish school of rehabilitation and the vision of optimizing social care actions. The purpose of the article is therefore to present facts concerning social exclusion of the disabled but also stresses how to make an attempt in order to counteract such phenomenon. In addition, the research was aimed to present good inclusion practices. Nowadays, disability has no longer been treated as a problem of psychological and cultural character. Disabled people are not perceived as those who are worse and may be ignored by the society or socially alienated. The issue itself has become a problem of institutional and legal nature (unclear legal regulations or inappropriate acting services). Current economic situation of the disabled in Poland in spite of time flows since its political transformation has not been properly resolved in numerous issues, still remaining unstable and insecure. Negative social phenomena such as poverty, unemployment, helplessness not only fail to disappear, but they are increasing evolving into other forms, touching with its unique consequences those who are the weakest or insecure. It needs to be pointed out that growing inequalities result from unequal (often unfair distribution of financial resources and reflect in integration and inclusion barriers and also their results as social problems which again have its source in exclusion (often interchangeably named as a social exclusion).
\end{abstract}

Keywords: Exclusion, social inclusion, inclusive education, disability, person with disabilities.

\section{INTRODUCTION}

It was already in the 90 's of the $20^{\text {th }}$ century when numerous research proved the stereotype meaning, which in fact was not far from its historical meaning. "Their image - as imperfect combined most common negative features attributed to a disabled person as weak, suspicious, complaining, fearful, hidden, insecure, lonely and poor. Disabled people were perceived as the ones who rather deserved sympathy and call for help rather than partners who do not possess certain restrictions but also opportunities" [1].

Nowadays disability has no longer been treated as a problem of psychological and cultural character. Disabled people are not perceived as those who are worse and may be ignored by the society or socially alienated. The issue itself has become a problem of institutional and legal nature (unclear legal regulations or inappropriate acting services [1].

\section{SOCIAL EXCLUSION AMONG THE MECHANISMS OF COLLECTIVE LIFE}

Current economical situation of the disabled in Poland in spite of time flow since its political transformation has not been properly resolved in numerous issues, still remaining unstable and insecure. Negative social phenomena such as poverty, unemployment, helplessness not only fail to disappear but they are increasing evolving into other forms, touching with its unique consequences those who are the weakest or insecure. It needs to be pointed out that growing inequalities result from unequal (often unfair distribution of financial resources and reflect in integration and inclusion barriers and also their results as social problems which again have its source in exclusion (often interchangeably named as a social exclusion).

The above mentioned meanings currently belong to the group of most common discussed phenomena in social and scientific area. It is worth to quote their definitions at the research initial stage. The term of social exclusion is commonly thought and identical with the notion of exclusion. Interchangeable character of these two expressions proves to be fully reasonable. Social exclusion is a direct translation of the English term as well as exclusion sociale found in French, which have been 
incorporated in Polish terminology. In the past it was commonly referred to in Poland as social exclusion and within time it has decreased its meaning towards exclusion [2]. K. Frieske rightly noticed that the fact of giving the meaning and taking up actions towards the issue of exclusion processes and marginality is not the result of sudden emerge of exclusion areas. It is obvious that together with existence of any society these must have shaped their boundaries, margins and spheres of social exclusion. No drastic changes have happened in most basic mechanisms of social life. The fact that exclusion is becoming a widely discussed topic results from the changes in the hierarchy of assessment and political priorities commonly shaping the structure of the problems we refer to with importance [3].

\section{DEFINITION OF THE CONCEPT OF SOCIAL EXCLUSION}

Social exclusion becomes a very problematic issue both within the sphere of defining but also areas concerning its causes and mechanisms which influence its shape. No matter controversies which it may arise, the concept of social exclusion is both used in the study of poverty and unemployment problem but also in defining phenomena from outside dominant current of social life. Social exclusion has numerous connotations of different nature i.e. social and economic, political and cultural. It also has a different individual local and global context. The category does not only refer to the unemployed or the poor. Among the excluded we may find socially accepted groups e.g. the sick or disabled but also those labeled with social disapproval e.g. prisoners, prostitutes or those who evade work. It needs to be mentioned that social exclusion is a multi-level phenomenon and it comprises " a variety of life situations which determine an individual and groups on worse social positions on the margin of social life out of mainstream" [4, p. 10].

Social exclusion is undoubtedly a heterogeneous meaning which combines complex and unstable class of phenomena. The group of socially excluded is externally and internally differentiated. Moreover, we may also say about few commonly combined spheres of social exclusion. Among those who are at risk of social exclusion are not only disabled but also homeless, long term unemployed, minority nationalities and ethnicity members, children and the children and the youth who lack of parental care, children brought up away from their families, women out of the job market, single parent mothers, immigrants, victims of family pathologies, the insane, those of low professional skills and qualifications, people who leave youth offenders institutions and prison but also those who live in difficult living conditions [5].

The term of social exclusion has replaced its previous meanings of poverty or subclasses (underclasses). It may be referred to life as whole or its individual segments such as job, education or consumption. It may be analyzed both in process and statistical context. It is an important object of social, educational and legal scientific research. It has the opposite meaning to integration, unity and inclusion [5]

By the term of social exclusion it can be meant as ordinary situations when a group becomes unable to participate in important aspects of social life, experience poverty and deprivation and cannot benefit their rights [6, p.48-49]. The definition of social exclusion was finally shaped in the document of "the National Strategy of Social Integration for Poland" and states that "lack or restriction of possibility to participate, influence and making use of basic public institutions and markets opposes the idea of common availability" [7, p. 22]. "Social exclusion which briefly saying - is based on taking up usual and socially accepted way of life or falling out of it, refers to people, families or groups which live in unfavorable economic conditions (material poverty), they are touched with adverse social processes which result from mass and dynamic development changes e.g. deindustrialization, economic crisis, sudden decline of branches or regions, those who have not been secured by life capital which enables them normal social status, appropriate level of qualifications, entering the job market or starting with own family which additionally makes it hard to adapt to changing social and economic conditions, they do not have access to appropriate institutions to let them equip with life capital its growth and accumulation, which takes place due to undergrowth of these institutions caused by the lack of priorities, public resources, low effectiveness functioning, they experience acts of discrimination, both due to undergrowth of proper legal regulations and cultural prejudice or stereotypes, they possess the features which make them difficult to exploit common social resources due to the occurrence of disability, addiction, long-term illness or other individual features and they become the subject of destructive actions from others e.g. violence, emotional blackmail, indoctrination [7, p. 21].

The field literature and other numerous state and international documents provide the definitions of social exclusion which "concentrate either on chosen dimensions or phenomena e.g. institutional and 
legal restrictions or dominant risk (threat against exclusion) for example poverty or lack of qualifications, or groups of people touched with social exclusion e.g. homeless, addicted or by revealing areas which have been restricted from the main source of consumption, information or culture. There are also formulated definitions describing the process of social exclusion by pointing out its major causes [7, p. 21].

Social exclusion is thus not only "multidimensional phenomenon which denotes inability to participate not only in economic life but also political, and first of all cultural one. It is the lack to resources, institutions and goods, restriction of social rights and deprivation of needs" [4]. There are four significant basic areas of social exclusion i.e. "excluding from job activity (unemployment disability), excluding from consumption (poverty), excluding from the mechanisms of influence and power (cultural and political marginality), excluding from society (loneliness)" [4]. An important aspect which explains the phenomenon of exclusion is an identification of basic issues, which are responsible for life situation of people who are touched with these processes [4]. These are "biological factors which become usually derivative of limiting own abilities, health conditions, physical fitness e.g. disabled, sick and mentally ill, market factors which are combined with job market competition, but also balance between supply and demand on fixed categories of job or professional education, for example low standard of education, unpopular jobs, inadequate qualifications, cultural factors resulting from different patterns, customs, values and beliefs e.g. religions, or ethnic minorities" [4].

\section{MARGINALIZATION AND SOCIAL EXCLUSION}

Social exclusion implicates combining few dimensions of marginality at a time and it means lack of possibility to take up unconsciously socially accepted, habitual way of life or falling out of it. It refers to people, families or groups to possess one or more positive features: "lack of access to appropriate institutions which allow to equip in life capital its development and growth which occurs e.g. due to underdevelopment of these institutions caused by the lack of priorities, lack of public resources, low effectiveness of functioning; lack of life capital which enables to maintain social position, appropriate level of qualifications, entering the job market or setting up own family may which again may cause difficulty to adopt to changing social and economic conditions; experience of destructive force from the others, e.g.: violence, blackmail, indoctrination, experience acts of discrimination which result from inappropriate working legal procedures, cultural prejudice and stereotypes; while experiencing unfavorable social processes which result from mass and dynamic development changes e.g. deindustrialization, crisis, sudden decline of the branch areas or regions, possessing features which make it difficult to use common social resources due to disability, addiction, prolonged Illness or any other individual features; life in unfavorable economic conditions (material poverty); exclusion; breaking bonds with the rest of society; multi-dimensional phenomena, permanent and enforced by degradation of common material or cultural resources and unfavorable situation" [5, p. 5].

The paradox is that it is commonly known, what should be done in the issue of preventing social exclusion among those who are in the group of increased risk including those with disabilities. To prevent such situations there are special regulations drew up. They include conclusions and arrangements which refer to: "treating counteraction poverty and exclusion as a priority of social policy; treating fighting poverty and exclusion not as the domain of social care but an integrated social policy; understanding expenditures on social policy not as the cost but pro-growth enterprise; change in allocating the outlays to support social safety instead of looking for money cuts in social sphere; providing more public resources on services and material benefits; providing larger public resources for politics which its future beneficiary will be children and families with children" [8].

The above actions should take into account experience and tradition of Polish school of rehabilitation which are known for their common character and complexity, holism and early initiation. They are characterized by the respect towards an individual, take into account life reality, they are suitable for an individual position and needs, combine education with improvement and care. They date back to the vision of social care system activities towards supporting the weak who are still IN-"dispensable" [9]. The point is that it "requires legal state regulations which may allow for creating programmes of a global life planning with rational exploitation of disabled people potential - competences achieved by them during the process of education and the use of their strength potential" [5, p. 8].

Moreover, it would be reasonable to follow the ways of active social policy already known in the 90's of the 20th century, which are included in two strategies. The first one refers to integration rehab which "is aimed at standardization and equality of chances through: economic and housing safety, providing means of transport and communication, education - adequate to one's interests, abilities and needs, 
access to job market (especially within open market), safety of intimacy and privacy, having a family and family life, participating in culture, acceptance and respect from the others. An essential condition becomes physical integration implicating reduction of architectural barriers and more difficult functional and psychological integration" [5, p. 8]. The second strategy means educating towards rehabilitation which is based on "adapting professional education training system to the needs of the job market, having in mind possibility for the disabled (jobs tailored for man's needs and abilities), actions taken up towards employers and disabled, organizing professional training and effects on surrounding environment - creating understanding the need of employing a disabled person, growth of employment opportunities. It needs to have in mind thesis to let him use all his individual potential" [5, p. 8].

\section{IN THE DIRECTION OF STRENGTHENING THE INCLUSION PROCESSES}

A community can significantly contribute to improvement of life quality of those who are within an increased risk of social exclusion occurrence. Advisably it is worth to provide social and family benefits, health care, favourable tax regulations, programmes supporting balance between professional job, especially among the mothers, and family life, enforcing the fulfillment of alimonies. It is the key and most important issue to care for high quality of education and rehabilitation. "Such programme may stimulate physical, cognitive, social and emotional growth - in other words it means a balanced, multi-dimensional and harmonious scheme. It can significantly change long-term trajectory of an individual's life. Calculated approximate analysis of costs and profits illustrate that such enterprise pays twice in the future" [10]. "Ethics may thus be combined with economy - using rational thinking - and not to escape in utopian visions which claim that educational integration will provide solution to any problem of the disabled and the family will cope with the situation as a self- repairing balanced system" [5, p. 11].

A specific solution to the problem of the disabled full of their realistic engagement in their varied forms of activity in the sphere of activity taken up by the society becomes an inclusive education, formerly called integrational. Moreover, implementing the system of inclusive education at initial stages of educating based on the idea of " a school for everyone" becomes a chance for each individual towards better future by effective counteracting segregation, marginality, exclusion of those with disabilities, illnesses or any other reasons. It needs to be stressed that the above reveals a significance of integration and inclusion issue. It was accurately pointed out by an outstanding contemporary researcher of inclusion processes, Tamara Zacharuk, saying that "a new paradigm in education coming towards the discussed problems can be regarded as inclusive (including) education. It gives a chance to all those who live on the edge and neglected to gain education which means that it allows fulfillment of the right to education for an individual. Inclusion raises important issues of children's right to attend global school which provides support for proper development, a place where he should be respected and praised for his own individuality. It needs to be understood as expending practice and school policy of equal opportunities. All that requires sacrifice from the teachers, authorities, parents and finally the children (...) Inclusive education refers to disabled children who study efficiently at global schools with an emphasis to the quality of education. In case of inclusive education it is not the child but the system which needs to be changed. Inclusive education "has grown out" of a social model of disability. It states that children differ from each other and following both the school and the system of education need to be changed to meet individual needs of all the students - either healthy or those with special educational needs. However, inclusion does not mean assimilation or making all the students equal. A key factor is flexibility - understanding that they study at different pace and the teachers require special skills to support these children in the process of learning in a flexible way. In most cases children simply need clear and common education. It requires to make a use of varied methods in order to meet numerous children's needs appropriate to their abilities and different pace of growth" [11]

\section{PUPIL IN THE SYSTEM OF INCLUSIVE EDUCATIONAL ACTIVITIES}

Sometimes it is claimed that "the meaning of integration traditionally refers to teaching children with special needs in public schools while the term of inclusion has much deeper meaning not only combined with education but also the feeling of local environment affiliation, participation in varied cultures and their transformations but also an attitude accepting students' indifference and their subjectivity. In such context inclusion is a process which undergoes on three levels: open social environment - including strategies of educational system - educational inclusion, educational 
influence - inclusive education" [12]. "Inclusion is a complexed process of providing a disabled with an opportunity to fulfill his development tasks, functioning in a larger society and the sense of being its member. Educational inclusion is a strategy to provide students with special educational needs the access to generally available public schools, local educational centres, taking into account individually fitted environment and the least restricting growth of the student with disability. Inclusive education is a process of common education offered to students with special needs together with their able-bodied peers, providing the feeling of being a member of the local community and necessary support (technical, methodological, psycho- social, organizational) which result from disability" [12]. Inclusion is a new educational system which demands radical changes referred to the concept of education, its organization, place and role of members of the process, opportunity to evaluate implemented structural, organizational and circular modifications" [12]. The system of inclusive education determines a detailed analysis of a disabled student situation, his family and peer environment where the process of common education undergoes. The participants of the process of inclusion comprise: the student with special needs, parents/guardians, teachers, other specialists but also peer and local environment. Thanks to inclusive education all the members of the process should be provided with favourable conditions for their functioning. A disabled student in a such system should be able to fulfill his needs whereas an able-bodied should have opportunity towards a wider growth. Parents of a disabled student should be supported with help while the parents of an able-bodied should be assured that such an educational solution is useful and optimal.

In Polish reality it is not a question of access to education, but its quality. The latter rather depends in significant way from the competence of the teacher, educator, guardian, counselor or a tutor but also from his perception of the world and respecting human rights. Teachers should develop their educational and therapeutical competences. Other specialists should be aware in this system, that their actions towards diagnosis, counseling, professional and social rehabilitation will be successful, which again increases chances of the disabled towards successful life and achievements [12]. It needs to be stressed that "thanks to integration education an important social effect can be achieved. It brings a new way of thinking. Disabled people are learning to be active in life within the society while able-bodied learn about ordinary interactions with them" [13].

\section{CONCLUSIONS}

The history of thought on the need of equal access to education and equal treatment of an individual regardless of his background and different intellectual abilities, even though they have been shaped by legal regulations it does not mean that daily social practice, including that of an educational one, fully satisfies access and equal educational chances of children and the youth endangered with social exclusion. International programmes may support the actions of teachers, guardians local and state authorities, social institutions however these acts are still not identical with the changes at the level of consciousness. It needs to be remembered that in order to make aware of the fact of inclusion in people's mind it requires increased intellectual thought among the practitioners of education, who firstly need to state openly that vast of their practice and way of thinking to date was or still is based on "rather medical scheme of disability". Following they should offer their sincere will to support "social scheme of disability". In her opinion Tamara Zacharuk claims that "schools which ambition becomes implementing inclusion principles, need constant involvement in the work of own research strategies, which allow for successful diagnosis of different types of environment barriers, search for new teaching and learning strategies, recognize attitudes and behavior either supporting or hinder accomplishment of social inclusion and modify the principles of organization and management. Inclusion is not a permanent state. It is a continuous process of school ethos changes: concerning building a school society, which not only accepts but even praises indifference" [11]. The change certainly requires a length of time, understanding varied needs of people with disability, but also self activity among those who are in need. Without any doubt, indispensable there becomes an instant reflection and a team work of theory and practice educators in the area signaled in this monograph, which becomes a significant issue of contemporary social phenomena.

\section{REFERENCES}

[1] A. Ostrowska, „Niepełnosprawni w społeczeństwie” in Badania nad niepełnosprawnością w Polsce (A. Ostrowska, eds.), p. 43, 95, Warszawa: Wydawnictwo IFiS PAN, 1994.

[2] E. Tarkowska, "Categories of social exclusion and its Polish reality" in Condemned to exclusion (M. Orłowska, eds.), Warsaw: 2005. 
[3] K. Frieske, „Dynamics of a social marginality concept”, 2002. http://www.ipiss.com.pl/polspo/konferencja2002/frieske.doc

[4] J. Grotowska-Leder, K. Faliszek (eds.), Social exclusion and inclusion: diagnosis - social factors - acting directions. Toruń: Akapit Publisher, 2005, pp. 10, 28-29.

[5] H. Żuraw, „Preventing social exclusion among people with intellectual disability”, ORE, p. 5, 8, 11. https://www.ore.edu.pl/wp-content/plugins/downloadattachments/includes/download. php?id=3441

[6] B. Gaś, Prevention at school. Warsaw: WSiP S.A, 2006, pp. 48-49.

[7] „National Strategy of Social Integration for Poland”, pp.21-22, http://www.mpips.gov.pl/userfiles/File/mps/NSIS.pdf

[8] R. Szarfenberg, Marginality and social exclusion. Lectures, the Institute of Social Policy. Warsaw: University, 2006.

[9] A. Hulek (ed.), Coherent system of social services towards invalids and disabled people. Warsaw: TWK Publisher, 1991.

[10] R. Wilkinson, K. Pickett, Spirit of equality. Everyone lives better life in equality surrounding. Warsaw: Czarna Owca, 2011.

[11] T. Zacharuk, B. Bocian, "Inclusion education - a new educational perspective. A student with special educational needs", Mazovian Education, No. 02 (07) 05, p. 5, 2011.

[12] J. Głodkowska, "In search for inclusion model education", Meritum, No. 2, p. 6, 2009.

[13] А. Бобрык, "Общественное значение интеграционного высшего образования инвалидов" in Куляшоўскія чытанні. Частка першая (М. І. Вішнеўскі, еd.), р. 21, Магілёў, 2004. 